\title{
Spatiotemporal Contingencies in Tourists' Intradiurnal Mobility Patterns
}

\author{
A. Yair Grinberger' and Noam Shoval ${ }^{2}$
}

\begin{abstract}
Tourists' activity patterns result from complex interactions between time-space constraints and cognitive, social, cultural, and emotional factors. Accordingly, tourists' intradestination activity is studied today from multiple perspectives. Yet knowledge regarding the interrelationships between these factors is limited. The current research aims to contribute to the bridging of this gap, by studying tourists' activity patterns and the time-space resource allocation decisions they reflect. Using a smartphone application, 384 tourists' activity days in the cities of Tel-Aviv and Jerusalem were tracked and characterized in terms of resource allocation patterns, identifying three distinct behavioral patterns. The effects of various personal and external factors on group membership were then assessed. The results uncover complex relationships between various decision-making dimensions, where interdimensional interactions occur at multiple spatial scales and decision-making instances. These findings suggest that activity patterns emerge from a decision time-space in which effects are contingent upon each other across scales and behavioral dimensions.
\end{abstract}

\section{Keywords}

time-space, spatial behavior, intradestination behavior, GPS, spatial cognition

\section{Introduction}

The rise of tourism as an important economic activity has led to the formation of tourism studies as a distinct research field (Archer, Cooper, and Ruhanen 2005; Butler 1980; Correia and Kozak 2017; Mayer et al. 2010). Tourism geographies had attracted much of the attention in this field because of this activity's spatially explicit nature. The introduction of advanced tracking technologies, such as the global positioning system (GPS), over the last decade has made observing tourists' behaviors with much detail and precision possible, thus promoting more research on intradestination behaviors (De Cantis et al. 2016; Grinberger, Shoval, and McKercher 2014; Hallo et al. 2012; McKercher et al. 2012, 2015; Shoval et al. 2011; Shoval and Isaacson 2007a, 2007b; Shoval, Schvimer, and Tamir 2017; Zhang, Huang, and Li 2017; Zillinger 2007; Zoltan and McKercher 2015). These studies are naturally related to the study of spatial behavior, a welldeveloped area of research within the field of geography (e.g., Walmsley and Jenkins 1992; Xiao-Ting and Bi-Hu 2012; Zhao et al. 2015; Zillinger 2007).

Behavioral geography, as a distinct research field, offers many insights regarding the motives and causes behind individuals' daily spatiotemporal choices (Golledge 2008). These insights relate to the nature of the decision-making process (Golledge and Stimson 1997; Strauss 2008; Wolpert 1964), its cognitive foundations (Downs and Stea 1973; Kitchin 1994; Lynch 1960; Manley 2016; Manley, Addison, and Cheng 2015), the effects of external conditions and timespace constraints (Hägerstraand 1970; Long and Nelson
2013; Neutens, Schwanen, and Witlox 2011; Pred 1977), and also to the emotional, affectual, and cultural dimensions of behavior (Greenberg, Raanan, and Shoval 2014; McQuoid and Dijst 2012; Pile 2010). The relations between tourism geographies and time-space behavior are evident in a plethora of studies that incorporate behavioral-geographic ideas, such as the time-space budget (Xiao-Ting and Bi-Hu 2012; Zillinger 2007) and the cognitive map (Chang 2015; Guy, Curtis, and Crotts 1990; Pearce 1977; Walmsley and Jenkins 1992) into the study of intradestination behaviors. Yet, this reliance implies that the study of intradestination behavior suffers from the same constraints that plague behavioral studies in geography. One such issue is derived from overt spatial behavior being the result of a complex array of interrelationships between individual-specific and environmental factors (Chen et al. 2016; Golledge and Stimson 1997). Consequently, assessing the relative weight of each factor in the formation of behavioral patterns and identifying contingencies among effects present a great challenge within this type of studies (Chen et al. 2016).

\footnotetext{
'GIScience Research Group, Institute of Geography, Heidelberg University, Heidelberg, Germany

${ }^{2}$ Department of Geography, The Hebrew University of Jerusalem, Mt Scopus, Jerusalem, Israel

Corresponding Author:

A. Yair Grinberger, GIScience Research Group, Institute of Geography, Heidelberg University, Raum 003, Im Neuenheimer Feld 348, 69I20, Heidelberg, Germany.

Email: yair.grinberger@uni-heidelberg.de
} 
In this context, the development of advanced tracking technologies holds a unique potential, allowing researchers to capture individuals' behavioral patterns with much detail. Several studies over the last few years have shown how data collected via these methods can be used to uncover various effects within time-space behavior (in both tourism and behavioral studies; Grinberger, Shoval, and McKercher 2014; Manley 2016; Manley, Addison, and Cheng 2015; McKercher et al. 2012; Shoval et al. 2011). The research presented here joins these attempts, carried while considering multiple conceptual points of view on spatial behavior and using high-resolution data on tourists' behaviors. As such, its main objective is to produce new insights regarding contingencies between the factors that affect tourists' spatial behavior. This study uses a unique dataset that captures the behavior of tourists in Israel during their entire visit. A comparative analysis of this dataset identifies the similarities and differences in behaviors over two main urban destinations. As such, the analysis allows distinguishing between factors that exert a general influence, to those that are site- or individualspecific by nature (or combine both). Thus, this research contributes new knowledge regarding the hierarchical character of influences on time-space behavior, and contingencies that exist within it.

The article continues as follows. First, we present a review of related literature to identify the relevant theoretical background for this study. The second section introduces the database and discusses processing and analysis steps. The next section details the empirical results. The paper then concludes with a discussion of the findings, their theoretical significance, and the implication of these for the study of tourist and general time-space behaviors.

\section{Literature Review}

\section{Time Geography}

This article relies mainly on the research framework known as time-geography (TG). TG is a conceptual framework for the analysis of time-space behavior, developed by Torsten Hägerstraand and his students (Ellegård and Svedin 2012). The main argument within TG is that the study of spatial behavior must include a consideration of time, as each instance of such behavior (e.g., participation in activity, movement) requires the allocation of time resources (Hägerstraand 1970; Neutens, Schwanen, and Witlox 2011). Given that the human body is indivisible, allocation of time resources to one type of activity necessarily implies that less time would be available for other activities (Neutens, Schwanen, and Witlox 2011; Pred 1977). For example, for tourists, allocating more time for a stationary activity (e.g., visiting an attraction) means less time would be available to explore the destination. As this latter activity requires the consumption of a "space" resource, TG identifies time and space as substitute resources. Furthermore, the "amount" of

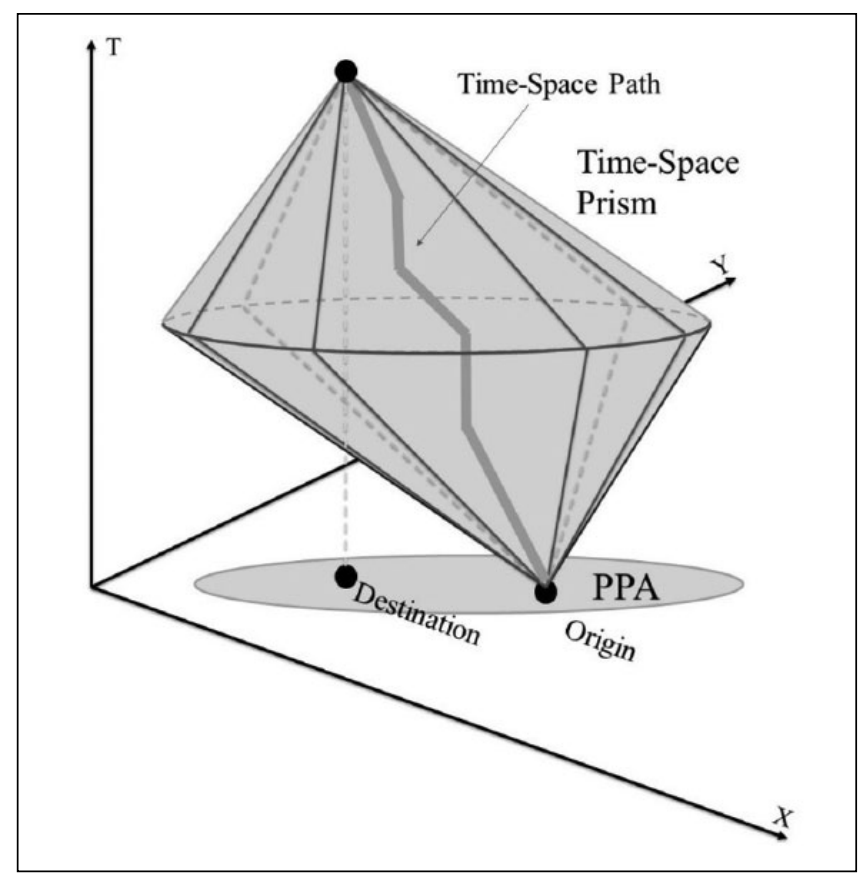

Figure I. Basic time-geographical entities.

time-space resources available to the individual is identified to be limited by several types of constraints (Hägerstraand 1970; Long and Nelson 2013; Pred 1977): capability constraints, which relate to the physical needs and abilities of the individual; coupling constraints, which result from the need to coordinate activities with the schedules of other individuals and objects; authority constraints, emerging from the set of laws and norms that apply within a specific time-space "domain."

The implications of such constraints, when interacted with goals and purposes that guide spatial behavior, is that behavioral patterns are organized around a set of spatially and/or temporally fixed activities (known as "stations"; Neutens, Schwanen, and Witlox 2011; Pred 1977). Activity (mobile or stationary) within the time-spaces near these stations are constrained by a limited activity time budget, set by the temporal attributes of the stations. This conceptualization of behavior informs the development of several fundamental time-geographic concepts. One such concept is the time-space prism, a formal and graphical representation of accessible activity space at each time instance, as determined by the spatiotemporal attributes of two subsequent stations and other constraints on mobility, such as speed limits (Lenntorp 1976; Miller 1991; Neutens, Schwanen, and Witlox 2011). The prism encompasses all time-space locations for which visit probability is above zero for the individual. Its graphical representation is a three-dimensional polygon, where the $X$ and $Y$ axes represent space, and time being the third dimension (see Figure 1). When this polygon is projected onto a 2-dimensional space, the potential path area (PPA) is identified-a representation of an individual's maximum geographical 
reach given a set of spatiotemporal constraints. The individual's actual time-space path (see Figure 1), that is, the set of time-space locations visited during a specific time-period, must be traversed within the boundaries of this area.

TG presents a valuable foundation for explorations in many mobility-related fields, and studies using it have managed to produce important insights regarding issues such as the effects of gender on behavior (Kwan 1999), the relations between transport and activity (Ellegård and Svedin 2012), and even wildlife movement (Long and Nelson 2015). Yet, the reliance of TG on a very constrained view of time-space behavior arguably limits its relevance to the study of tourist behavior, given tourism's unique nature. Yet, tourists' behaviors are still very much constrained by many time-space elements, such as their personal capabilities, attractions and facilities operation hours, the capabilities of group members (when traveling in group), and the time available for activities (number of days, hours per day). The applicability of TG to the case of tourist activity is evident in a growing number of studies that use it to investigate the geographies of tourism (e.g., Grinberger, Shoval, and McKercher 2014; Shoval and Isaacson 2007a, 2007b; Xiao-Ting and Bi-Hu 2012; Zillinger 2007). The uniqueness of the tourist case within the TG framework lies in the enhanced freedom of choice that tourists enjoy within the boundaries of the prism. In other words, the tension between potential behavior (represented by the prism) and its specific realization requires more attention in TG-based tourism studies (Grinberger, Shoval, and McKercher 2014).

This realization is dependent on many elements; not all of them are spatiotemporal in nature. For example, multidestination travel is a phenomenon that was identified to be highly contingent on the spatial configuration of the destination (Kim and Fesenmaier 1990; Lue, Crompton, and Fesenmaier 1993). Nevertheless, elements such as preferences, decisionmaking procedures, perceptions, travel group composition, and cultural background also exert significant influences on travel sequencing, influences that exist alongside this spatiotemporal effect and interact with it (Bowden 2003; Hwang and Fesenmaier 2003; Hwang, Gertzel, and Fesenmaier 2006; Tideswell and Faulkner 1999). These effects are not entirely captured by the time-geographic framework, and are better considered by other conceptual points of view.

\section{Cognitive and Emotional Dimensions of Time- Space and Tourist Behavior}

When time-space conditions create a choice space, conscious decision-making behaviors, as well as cognitive biases and precognitive effects, determine spatiotemporal patterns. The classical model used to describe individuals' decision-making processes is that of the rational decision maker - an all-knowing, utility-maximizing individual (Chen et al. 2016; Strauss 2008). Stemming from the understanding that this model does not reflect real-life choice-making procedures (Kahneman and Tversky 1979; Simon 1955, 1972; Thaler 1980, 1985), the subfield of behavioral geography has emerged (Golledge 2008; McCormack and Schwanen 2011). Studies in this subfield use disaggregated individual-level data to study actual behaviors, producing more descriptive (instead of normative) models of spatial behavior (Golledge 2008). As such, the field has quickly turned to studying individuals' cognitive representations of the external world and their accuracy as a critical factor that informs behavioral choices (Couclelis et al. 1987; Downs and Stea 1973; Kitchin 1994; Lynch 1960). Such representations are constructed from knowledge gathered via personal experience or secondhand information (e.g., maps, images, and textual information; Richardson, Montello, and Hegarty 1999). Individuals' cognitive maps are known to be distorted, thus biasing locational and travel distance/duration estimations (Brunyé, Mahoney, and Taylor 2015; Tversky 1992; biases may vary by source of information-see Richardson, Montello, and Hegarty 1999). The amount of existing knowledge and the extent of its distortion influence behavior, at times leading to incongruence between intentions and actual behavior (Cadwallader 1975).

Yet, some behaviors are more intuitive or even automatic in nature, rather than being the result of well-crafted decision-making processes. In such cases, the cognitive element may be less important and precognitive elements, such as the emotional and the affectual dimensions, may prove to be the critical ones (Pile 2010). Furthermore, as spatial behavior is embedded within a social context, it may be guided by social structures, group decision-making processes, and power relations as well (McCormack and Schwanen 2011). While each of these factors cannot contradict the spatial reality within which behavior is carried, their effects may at times be strong enough to outweigh the constraining role of spatiotemporal conditions. This may be especially true when the choice margin is very large, such as in the case of tourism activities.

Factors from environmental psychology were suggested to be of relevance for tourism studies as early as the 1980s (Fridgen 1984) and indeed, the tourism literature shows some consideration of the roles of these factors in the formation of activity patterns. Tourists are known to develop a cognitive representation of the destination quite quickly, with the nature of this representation depending on familiarity with the destination, individual characteristics, and on the type of navigation aid used (Chang 2015; Fridgen 1987; Guy, Curtis, and Crotts 1990; Pearce 1977; Walmsley and Jenkins 1992). In addition, knowledge differences between first-time and repeat visitors, or between well-prepared and unprepared visitors, were found to affect both cognitive representation (Young 1999) and observed behavioral patterns (Bauder and Freytag 2015; McKercher et al. 2012). Yet, tourism is largely an activity motivated by precognitive and emotional effects that may define the entire tourist experience (Massara and Severino 2013). This is evident in the formation of destination images, relying on both "cognitive" and "affective" conceptions of the destination (San Martín and Rodríguez del 
Bosque 2008), and also in the final outcomes such as visitors' satisfaction and destination loyalty (Bigné and Andreu 2004; Yuskel, Yuskel, and Bilim 2010). In terms of intradestination behavior, cultural background has been shown to affect choices such as accommodation, mode of transport, and movement patterns (Dejbakhsh, Arrowsmith, and Jackson 2011) while behavior was claimed to change with activity context (Sarmento 2017). While these findings present new knowledge regarding the formation of behavioral patterns, they are limited in the sense that most of them relate to a subset of the multiple aspects motivating spatial behavior. While relating to all aspects may be beyond the scope of a single article, studying behavior from a more integrative point of view may prove to be beneficial in this context.

\section{Tourist Behaviors: Tracking and Trajectory Processing}

Many of the studies mentioned above use high-resolution activity data collected by means such as GPS loggers. This phenomenon is not new, as studies of tourism geographies have been frequently relying on data acquired via advanced tracking technologies for more than a decade now (Shoval and Ahas 2016). These methods replace more traditional observation methods, such as the travel diary and participating observations (Shoval and Isaacson 2007a). These novel methods, which also include passive tracking via cellular networks and social network data, have given rise to a new generation of tourism studies that have produced new insights regarding fundamental questions in the field (Shoval and Ahas 2016). This is not the case only in the field of tourism, and tracking data were already used to produce findings regarding the cognitive (Manley 2016; Manley, Addison, and Cheng 2015), emotional (Shoval, Schvimer, and Tamir 2017, 2018), and social (Slim and Ahas 2016) dimensions of human spatial behavior.

The growing availability of spatiotemporal data calls for the development of approaches for processing and analyzing these data. This need is answered within the realm of trajectory pattern analysis, a field of research focused on the development of methods for analyzing time-space trajectories (the collection of traces depicting the movement of objects during a specific time-period; Nanni and Pedreschi 2006). As sampling conditions are rarely optimal, such data can be incomplete or inaccurate at times. Consequently, raw trajectory data need to be preprocessed, with steps like outlier identification, track smoothing, and map-matching commonly employed (Yan et al. 2013). Furthermore, trajectories in their raw form are rarely useful and most analyses require further processing steps, such as segmenting the data into stops and movements (Renso et al. 2013) or semantically enriching trajectories with information from some other data repositories (Gong et al. 2014; Yan et al. 2013).

Upon the completion of the preprocessing stage, the analysis of trajectories is usually carried with the objective of measuring the similarity between different trajectories and clustering those together, thus identifying general behavioral patterns (i.e., trajectory pattern mining; D'Urso and Massari 2013). This approach was implemented in the context of tourism using social media data (Bermingham and Lee 2014; Yin et al. 2011) and GPS-based trajectories (Shoval and Isaacson 2007b; Tchetchik, Fleischer, and Shoval 2009). Yet, this descriptive approach is not enough to achieve a fundamental understanding of the reasons behind tourists' observed space-time behaviors. Therefore, while this study uses an approach that generally follows the trajectory pattern mining approach, more analysis steps are carried to expose the intertwined contributions of the cognitive, emotional, and cultural dimensions to the formation of identified patterns.

\section{Methodology}

\section{Analysis Approach}

The approach utilized in this research follows the one presented by Grinberger, Shoval, and McKercher (2014). This approach, rooted in time-geographic thinking, aims at clustering tourists' trajectories according to the time-space resource allocation behaviors they reflect. For example, a tendency to cluster stops together would lead to the minimization of travel times, thus reflecting a bias toward maximizing the consumption of the time resource. Yet, a movement path not following the shortest or fastest route between these stops would result in more spatially explorative behaviors, thus indicating a preference towards the space resource.

The approach consists of three steps. First, raw trajectories are transformed into segmented (or structured/syntactic) trajectories via a stop-and-movement identification procedure, a process in which a movement trajectory is broken down into stationary ("stop") and mobile behavior episodes. Second, two network-based time-space measures are computed for each trajectory: the average distance between pairs of subsequent stops ("average stop distance"; computed using fastest/shortest route distances) and the ratio between the length of the shortest route along the sequence of stops (in their original order) to the distance actually traveled ("movement efficiency"). The first measure indicates the extent to which stops cluster in space while the latter relates to the extent to which chosen paths show travel-time efficiency. Finally, trajectories are clustered according to these measures' values using the $\mathrm{K}$-means algorithm. These identified clusters represent and characterize general behavioral patterns displayed by tourists within a destination.

This study includes an additional analysis step that studies the effects of different factors on the emergence of identified patterns. This step analyzes the relations between individual-, site-, and activity-specific variables and the emergence of different behavioral patterns by performing a multinomial logistic regression. 
Table I. Sample Characteristics.

\begin{tabular}{lc}
\hline Variable & Value \\
\hline Purpose, 'no. of participants (\% of sample) & \\
Business & $356(26.27 \%)$ \\
Visiting family and friends & $691(51.00 \%)$ \\
Religious visit & $113(8.34 \%)$ \\
Touring & $839(61.92 \%)$ \\
Other / no data & $9(0.66 \%)$ \\
Religious affiliation, no. of participants (\% of sample) & \\
Jewish, religious & $232(17.12 \%)$ \\
Jewish, other & $370(27.31 \%)$ \\
Christian & $424(31.29 \%)$ \\
Muslim & $5(0.37 \%)$ \\
Other/no data & $324(23.91 \%)$ \\
Visit duration, average no. of nights (SD) & $6.88(3.24)$ \\
First-time visitor, no. of participants (\% of sample) & \\
Yes & $541(39.93 \%)$ \\
No & $813(60.00 \%)$ \\
No data & $1(0.07 \%)$ \\
Region of residence, no. of participants (\% of sample) & \\
North America & $422(31.14 \%)$ \\
South America & $40(2.95 \%)$ \\
Western Europe & $723(53.36 \%)$ \\
Eastern Europe & $87(6.42 \%)$ \\
Asia & $25(1.85 \%)$ \\
Africa & $24(1.77 \%)$ \\
Australia and the South Pacific & $20(1.48 \%)$ \\
No data & $14(1.03 \%)$ \\
Visiting group size, average size (SD) & $1.71(0.99)$ \\
Visiting group composition, no. of participants (\% of sample) \\
Groups with children (ages 0-I8) & $133(9.82 \%)$ \\
Groups with elderly members (ages 60+) & $203(14.98 \%)$ \\
\hline
\end{tabular}

'Up to two different purposes were indicated by each participant.

\section{Database}

The database used in this research includes GPS traces depicting the movement of tourists in Israel, all through their visit, collected as part of a tourist travel survey carried by the Jerusalem Transport Master-Plan Team (JTMT). Tourists were approached by representatives of the JTMT upon arriving at Ben Gurion airport in Israel and were offered to participate in the research in exchange for a smartphone, a communication package offering unlimited local text messaging and $3 \mathrm{G}$ surfing, and a $\$ 40$-worth coupon applicable in the airport's Duty-Free store (distributed upon the successful completion of the survey). Tourists who agreed to participate filled a preliminary questionnaire, used to screen individuals visiting for more than 15 days or visiting as part of an organized group, and to control the sampling process so as to avoid oversampling specific populations. The questionnaire collected general sociodemographic and tourist profile data, such as country of origin, number of people in the visiting group, visit purposes, and number of previous visits (Table 1 presents the general characteristics of the sample). The surveyor then activated a location tracking application installed on the phone, which was set to sample location every 3 seconds. The application continuously uploaded the data to a main server, where imprecise traces were automatically filtered and trajectories were segmented into stop and movement episodes. Each evening, a representative of the JTMT contacted the tourist by phone and administered a short prompted-recall survey, based on the processed tracking data. As part of the survey, the surveyor asked the participant to indicate which activity (if any) took place during each of the identified stops and the mode of transport used to travel to its location. The participant also provided information regarding stops not captured in the processed trajectory (deu to the participant not carrying the phone with him or her, to a technical malfunction, or to the identification procedure simply not identifying it). In such a case, the surveyor added new stops to the data and labeled them as either "on path" (when they correlated with the tracking data) or "out of path." The participation ended on returning to the airport, where the participant filled a short satisfaction survey.

\section{Case Studies}

While the spatial extent of the database covers the entire state of Israel (as well as several locations in Jordan and Egypt), a national-level analysis would not make much sense in the current context, as the presence of interdestination movement would bias the analysis. In addition, multiple destinations imply multiple spatiotemporal behavioral contexts, thus making the interpretation of results an extremely complex task. Consequently, the analysis focused on two specific destinations - the cities of Tel-Aviv and Jerusalem (as well as municipalities in their close surroundings, such as Bethlehem for Jerusalem and Herzelia for TelAviv). These cities, while being two of the main tourist destinations in Israel, are very different in both character and spatial structure. Jerusalem is a city sacred to the three largest monotheistic religions, including sites such as the Temple Mount, the Wailing Wall, the Church of the Holy Sepulture in the Old City, and the Mount of Olives, alongside more modern sites such as the Yad Vashem Museum and the Mahne Yehuda Market (see Figure 2). The spatial distribution of attractions in Jerusalem is related to its topographically fragmented structure that includes many hills and valleys. Mobility is further constrained by the cultural context, as participation in activities in the Palestinian neighborhoods of Eastern Jerusalem or the city of Bethlehem may be unavailable to Jewish populations, or simply be (cognitively) unwelcoming.

Tel-Aviv, on the other hand, is the economic capital of Israel, connected to the global economic system. As such, it offers a variety of cultural, dining, and nightlife activities. None of its attractions is as salient as the main sites in Jerusalem and the dominant element in Tel-Aviv seems to be the beach of the Mediterranean Sea along which the city is located. The area is 


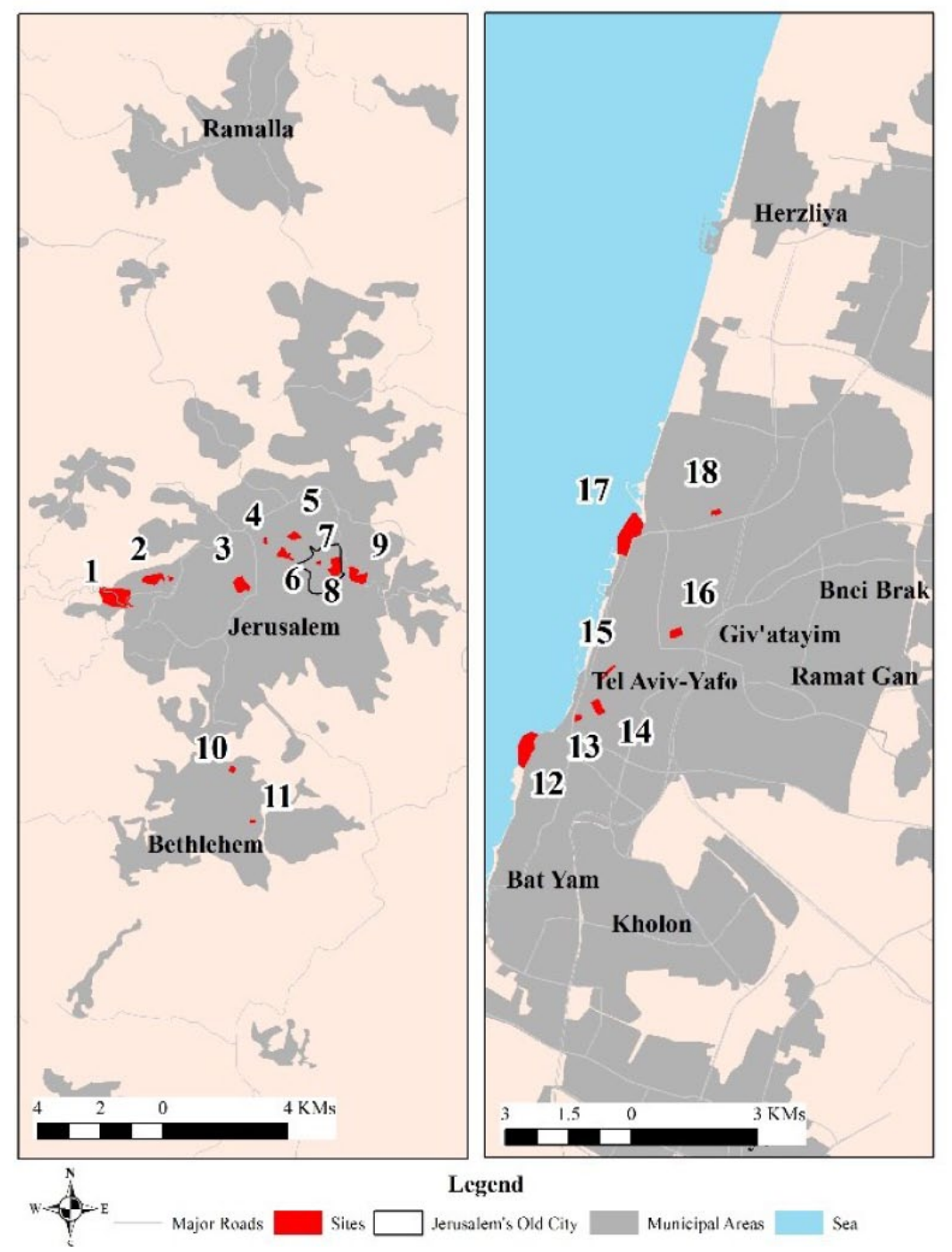

Figure 2. Selected sites in case study cities. Jerusalem: (I) Ein Karem, (2) Yad Vashem and Mount Herzel, (3) Israel Museum, (4) Mahne Yehuda market, (5) Mea She'arim, (6) City Center, (7) Church of the Holy Sepulcher, (8) Temple Mount, (9) Mount of Olives, (10) Rachel's Tomb, and (I I) Church of Nativity; Tel-Aviv: (I2) Jaffa Port, (I3) Hatakhana Campus, (14) Neve Tsedek, (I5) HaCarmel market, (16) Tel-Aviv Museum of Art, (17) Tel-Aviv Port, and (18) Erets Israel Museum.

relatively flat, meaning that topography does not exert a significant effect on mobility and that the city is generally accessible. The beach acts as a linear boundary in relation to which the city is organized. In accordance, tourist attractions in TelAviv almost form a continuum from the old city of Jaffa in the south to the old Port in the north (see Figure 2). Cultural and ethnic tensions are also rare in the city.

The choice of such contradicting pair of destinations was made deliberately. These contrasts allow differentiating between components of the behavioral decision regarding resource allocation related to the specific conditions in one site, to ones transcending the effects of specific time-space behavioral contexts.

\section{Preprocessing Steps}

As noted above, GPS data, although being much more precise than data produced via other tracking methods (such as cellular positioning), may still contain many errors due to interferences in reception, sensor malfunction, or misuse. Furthermore, data are valid only at times when the participant carried the logger. Finally, as the focus of this article is on the behavior of individuals, only nonorganized tourismrelated patterns were deemed as relevant for the analysis. In accordance with the above, we first carried several preprocessing stages, filtering invalid days from the data set and improving the quality of the data. 
Table 2. Preprocessing Steps and Derived Data Set Size.

\begin{tabular}{|c|c|c|c|c|c|}
\hline No. & Stage & Type & Exclusion Criteria/Processing Procedure & $\begin{array}{l}\text { Number of } \\
\text { Participants (\% } \\
\text { of Original Size) }\end{array}$ & $\begin{array}{l}\text { Number of } \\
\text { Activity Days (\% } \\
\text { of Original Size) }\end{array}$ \\
\hline- & Original data set & & & $\mathrm{I}, 355(100 \%)$ & $10,682(100 \%)$ \\
\hline 1 & Outlier identification & $\begin{array}{l}\text { Quality } \\
\text { improvement }\end{array}$ & See Appendix A & I,355 (100\%) & $10,682(100 \%)$ \\
\hline 2 & $\begin{array}{l}\text { Filtering by sampled } \\
\text { duration }\end{array}$ & Filtering & Total duration $<12$ hours & $1,349(99.56 \%)$ & $8,476(79.35 \%)$ \\
\hline 3 & $\begin{array}{l}\text { Filtering by } \\
\text { spatiotemporal gaps }\end{array}$ & Filtering & $\begin{array}{l}\text { Total duration of gaps }>10 \% \text { of total } \\
\text { duration. A gap is identified as a shift } \\
\text { in location } \geq 400 \mathrm{~m} \text { over an unsampled } \\
\text { period at least } 15 \text {-minutes-long }\end{array}$ & $1,306(96.38 \%)$ & $6,230(58.32 \%)$ \\
\hline 4 & $\begin{array}{l}\text { Filtering by "out-of-path" } \\
\text { reports }\end{array}$ & Filtering & $\begin{array}{l}\text { Total duration of reported "out-of-path" } \\
\text { periods }>10 \% \text { of the total duration }\end{array}$ & 1,302 (96.09\%) & $6,156(57.63 \%)$ \\
\hline 5 & Trajectory segmentation & Segmentation & See the "Analysis Specifications" subsection & $1,302(96.09 \%)$ & $6,156(57.63 \%)$ \\
\hline 6 & Track smoothing & $\begin{array}{l}\text { Quality } \\
\text { improvement }\end{array}$ & $\begin{array}{l}\text { Schuessler and Axhausen's (2009) Gauss- } \\
\text { Kernel location smoothing procedure; } \\
\text { temporal Kernel bandwidth = } 20 \text { seconds }\end{array}$ & $1,302(96.09 \%)$ & $6,156(57.63 \%)$ \\
\hline 7 & $\begin{array}{l}\text { Filtering by activities and } \\
\text { mode of transport }\end{array}$ & Filtering & $\begin{array}{l}\text { Day includes nontourism activities } \\
\text { or } \\
\text { does not include tourism activities } \\
\text { or } \\
\text { includes the use of organized transport }\end{array}$ & $985(72.69 \%)$ & $2,775(25.98 \%)$ \\
\hline 8 & $\begin{array}{l}\text { Filtering by stop-activity } \\
\text { matching }\end{array}$ & Filtering & $\begin{array}{l}\text { At least one unmatched tourism-related } \\
\text { activity exists; see Appendix B }\end{array}$ & $946(69.81 \%)$ & $2,529(23.67 \%)$ \\
\hline
\end{tabular}

These steps (summarized in Table 2) included first a phase of removing outlier samples (traces showing speed and acceleration values that are strikingly abnormal relative to traces recorded before and after them) from the database (see Table 2, step 1, and Appendix A). Then, invalid activity days were removed from the data set of each participant, based on the number of activity hours sampled in each day (step 2, Table 2), the existence of unsampled movement periods (i.e., "gaps") within the GPS data (step 3), or according to the amount of time the participant flagged as "out-of-path" (step 4). Finally, after more processing steps (steps 5 and 6; see the "analysis specifications" section), two more filtering steps were preformed (see Table 2), based on the types of activities reported in each day (focusing on unorganized tourism activities; step 7), and on the degree to which they match the GPS data (step 8). Matching included finding the most similar GPS-based stops, in terms of location and timing, for each of the reported activities (see Appendix B for the full description of the procedure).

This somewhat strict multistage filtering process, while required for increasing the validity of the analysis, greatly reduced the sample size (see Table 2). The choice of two specific case studies, and not the entire country, further aggravated the situation. To test whether the filtering process produced a biased dataset, the characteristics of the valid subsample were compared with those of the nonvalid sample $^{1}$ (see Table 3 ). While differences were relatively small for most variables, some significant incongruences existed. Some of these - the overrepresentation of "touring" visitors, the underrepresentation of business visitors, and the increase in number of nights - are the natural product of the filtering process (e.g., the longer the visit, the greater the probability that at least one day would be validly sampled). Yet in terms of representation of tourists visiting for religious purposes, of group size, and of the number of visitors traveling with children, the subsample displays some level of bias.

However, these biases did not seem to affect spatial coverage: a comparison of tourism activity density-surfaces ${ }^{2}$ for both the entire dataset (since the nonvalid dataset includes many inaccuracies) and the subsample of valid days shows that the coverage of the main touristic sites and areas did not change by much, despite a general decrease in coverage (Figure 3).

The analysis used only activity days from the final database, which included at least two tourism-related activities in one of the case study cities, resulting in a sample size of 384 activity days (188 for Jerusalem, 196 for Tel-Aviv) representing 285 participants.

\section{Analysis Specifications}

As noted above, the analysis procedure included three stages: the segmentation of raw trajectories into stop and movement episodes, the calculation of network-based time-space resource allocation measures, and the clustering of trajectories based on these measures. 
Table 3. Final Subsample Characteristics and Differences from Nonvalid Sample.

\begin{tabular}{|c|c|c|}
\hline Variable & Value & $\begin{array}{l}\text { Difference from } \\
\text { Nonvalid Subsample }\end{array}$ \\
\hline \multicolumn{3}{|l|}{ Purpose, no. of participants (\% of sample) } \\
\hline Business & 155 (16.38\%) & $-32.76 \%^{\mathrm{a}}$ \\
\hline Visiting family and friends & $502(53.06 \%)$ & $+6.86 \%$ \\
\hline Religious visit & $67(7.08 \%)$ & $+4.64 \%^{\mathrm{a}}$ \\
\hline Touring & $664(70.19 \%)$ & $+27.40 \%^{\mathrm{a}}$ \\
\hline Other / no data & $6(0.63 \%)$ & $-0.10 \%$ \\
\hline \multicolumn{3}{|c|}{ Religious affiliation, no. of participants (\% of sample) } \\
\hline Jewish, religious & 167 (17.65\%) & $+1.76 \%$ \\
\hline Jewish, other & $274(28.96 \%)$ & $+5.49 \%$ \\
\hline Christian & 291 (30.76\%) & $-1.76 \%$ \\
\hline Muslim & $0(0.00 \%)$ & $-0.82 \%^{\mathrm{a}}$ \\
\hline Other/no data & $214(22.62 \%)$ & $-3.45 \%$ \\
\hline Visit duration, average number of nights (SD) & $7.79(3.00)$ & $+3.01(+0.23)^{\mathrm{a}}$ \\
\hline \multicolumn{3}{|l|}{ First-time visitor, no. of participants (\% of sample) } \\
\hline Yes & $394(41.65 \%)$ & $+5.71 \%$ \\
\hline No & $55 \mathrm{I}(58.25 \%)$ & $-5.81 \%$ \\
\hline No data & I (0.1I\%) & $+0.11 \%$ \\
\hline \multicolumn{3}{|c|}{ Region of residence, no. of participants (\% of sample) } \\
\hline North America & $313(33.09 \%)$ & $+6.44 \%$ \\
\hline South America & $24(2.54 \%)$ & $-1.37 \%$ \\
\hline Western Europe & $496(52.43 \%)$ & $-3.07 \%$ \\
\hline Eastern Europe & $57(6.03 \%)$ & $-0.39 \%$ \\
\hline Asia & $13(1.37 \%)$ & $-1.30 \%$ \\
\hline Africa & $19(2.01 \%)$ & $+0.79 \%$ \\
\hline Australia and the South Pacific & $16(1.69 \%)$ & $+0.71 \%$ \\
\hline No data & $8(0.85 \%)$ & $-0.62 \%$ \\
\hline Visiting group size, average size (SD) & $1.83(1.07)$ & $+0.40(+0.36)^{\mathrm{a}}$ \\
\hline \multicolumn{3}{|c|}{ Visiting group composition, no. of participants (\% of sample) } \\
\hline Groups with children (ages $0-18$ ) & 112 ( $11.84 \%)$ & $+6.71 \%^{\mathrm{a}}$ \\
\hline Groups with elderly members (ages 60+) & 154 (16.28\%) & $+4.30 \%$ \\
\hline
\end{tabular}

${ }^{\mathrm{a}} 95 \%$ confidence level significance.

Segmentation of trajectories into stops and movement episodes was carried via a stop-identification procedure, which required three parameters: an intrastop maximal distance threshold, beyond which two traces were not considered to be part of the same episode ( $70 \mathrm{~m}$ here); a minimal duration threshold used to decide whether a set of subsequent points that satisfy the distance threshold indeed make a stop or just a momentary pause (300 seconds here); and an interstop minimal distance threshold used to merge subsequent stops that are located nearby $(100 \mathrm{~m}$ here $)$. The procedure iterated through all samples, and for each sample identified the sequence of subsequent points that satisfied the maximal distance threshold. The algorithm identified this sequence as a stop only if it also satisfied the minimal duration threshold. The location of each stop was set according to the average coordinates over all samples within the sequence (where the weight of each trace in this average was set by its duration, i.e., "duration-weighted" mean). If the distance between centers of two subsequent stops was below the value of the third parameter, the stops were merged into one stop and the mean center was recalculated.

The calculation of resource allocation measures was based only on stops that were matched with a tourism-related activity (each activity could have been matched with more than one stop). The shortest distance between each pair of stops was calculated using Google Maps API, while considering the mode of transport: if during an activity day the participant reported using a private car or a taxi, it was assumed that private vehicle-based transport was available to this individual throughout the day; otherwise only transit transport mode was considered. The distance between each pair of stops was set as the lower one between the shortest walking and the shortest vehiclebased (private or public) route distances. Vehicle-based routes were computed for a mid-week day, six months into the future, using Google's "best guess" estimation model. This meant that the estimation would rely mostly on Google Map's historical traffic data, thus avoiding a bias toward momentary conditions in the analysis. The average stop-distance measure was derived 

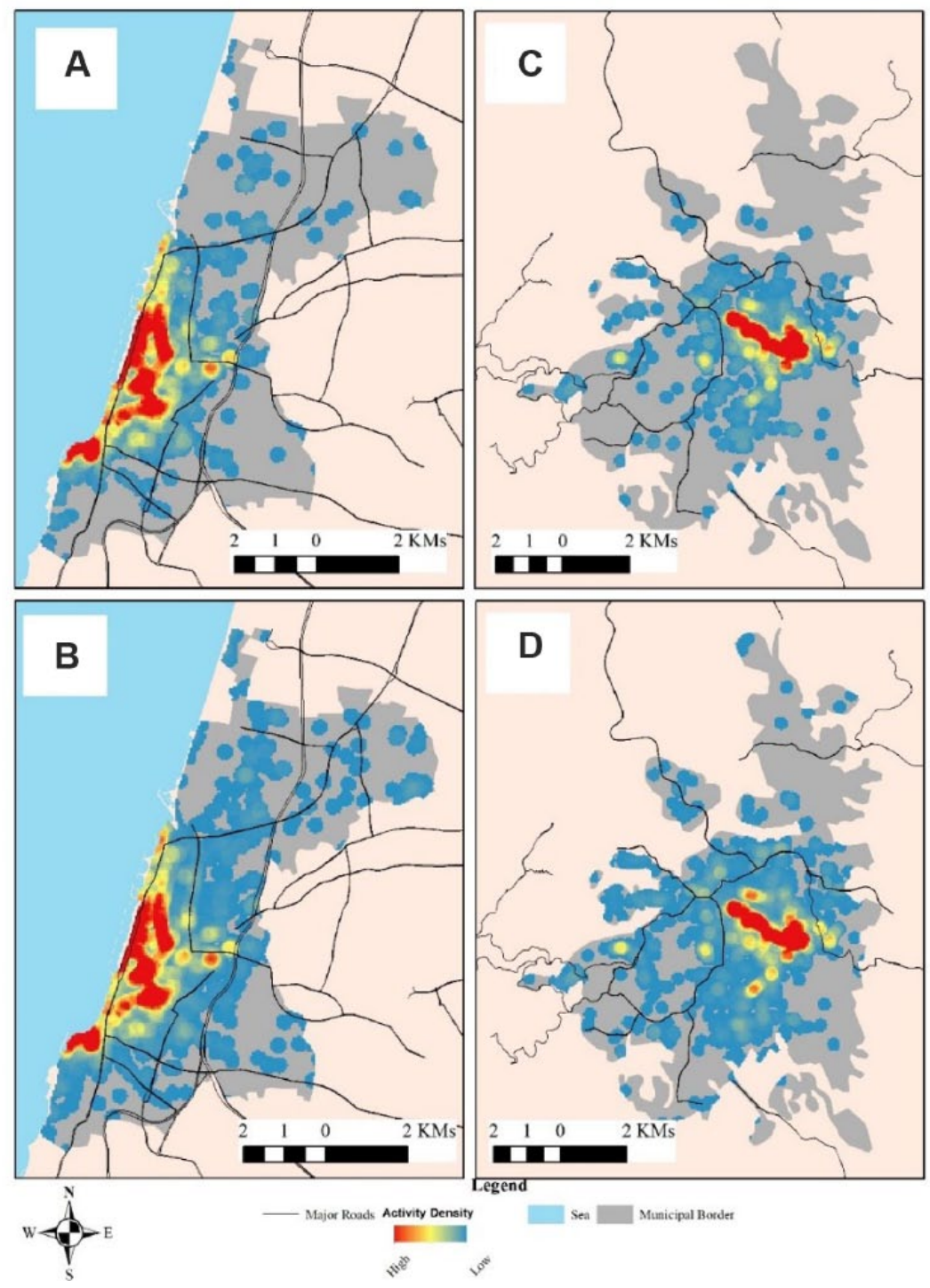

(age

W Sea 1 Municipal Border

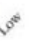

Figure 3. Tourism activity density surfaces for the entire sample and the valid days sub-samples. Tel-Aviv: (a) subsample, (b) entire sample; Jerusalem: (c) subsample, (d) entire sample.

by dividing the sum of distances between each pair of stops by the number of pairs minus 1. Movement efficiency was calculated by dividing this sum by the total length of measured movements between stops (aerial distances from the start point to the first movement trace and from the end point to the last trace were added to the length of observed routes). As the two measures use different units (meters per stop for average distance, percentage for movement efficiency), their values were normalized.

Finally, clustering was carried using the K-means clustering algorithm (McQueen 1967), using the relevant command in Stata 13.0. Following the findings of Grinberger, Shoval, and McKercher (2014), $K$ (the number of clusters parameter) was set to three.

\section{Results}

\section{Time-Space Resource Allocation}

As noted above, the two case studies chosen for the paper are strikingly different, presenting varying cultural and behavioral time-space environments. Therefore, the first issue that required consideration is whether these differences are large enough to affect the distribution of resource allocation behaviors within the population. Graphically (Figure 4), it seems that is not so, as the distribution of the data is quite similar between the two subsamples of visit days. Statistically, however, one difference was found as the movement efficiency values in Jerusalem $(\mathrm{M}=0.65, \mathrm{SD}=0.02)$ were significantly lower than in Tel-Aviv $(\mathrm{M}=0.73, \mathrm{SD}=0.02 ; t=-2.64 ; \mathrm{p}=0.009)$. 


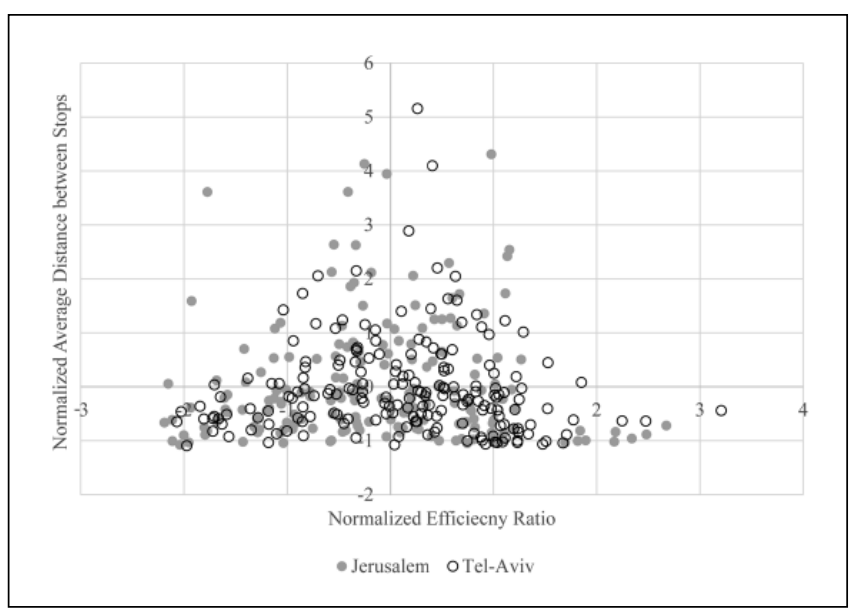

Figure 4. Distribution of time-space resource allocation measures' values.

Average distance between stops did not present such a significant effect (estimated using log values, Jerusalem: $\mathrm{M}=2.92$, $\mathrm{SD}=0.03$; Tel-Aviv: $\mathrm{M}=2.94, \mathrm{SD}=0.03 ; t=-0.38, \mathrm{p}=0.70$ ). In light of these partial differences, we chose to cluster the data as one sample and later test for differences.

Following Grinberger, Shoval, and McKercher (2014), clusters were characterized by comparing cluster-level and dataset-level average values. Each cluster was represented by a two-letter combination, the first letter representing relations between cluster-level and dataset's movement efficiency average values, and the second relating to the average value of average distances. Cases in which the cluster's average was higher than the dataset's were represented by the letter $\mathrm{H}$ (standing for higher than average), and $\mathrm{L}$ was used otherwise. For example, the combination HL indicated a cluster that presented, in relation to the average values over the entire dataset, a higher average efficiency ratio along with a lower average value of average distances. The three identified clusters (Figure 5A) represented distinct behavioral strategies, with the HL cluster representing a disposition toward maximizing activity time over space, and the other two reflecting substitution effects: in the $\mathrm{HH}$ cluster, tourists consume more space by increasing distances between stops, while in the LL cluster the same is achieved via inefficient movement routes. Interestingly, these results echoed Grinberger, Shoval, and McKercher's (2014) findings regarding the behavior of tourists in Hong Kong (Figure 5b). Differences between the two cases were evident in the share of each cluster out of the total sample - while in Hong Kong the largest cluster was the LL group (with an average size of $38.93,{ }^{3} 57.25 \%$ of the sample), in the current case clusters were more evenly distributed, with HL being the largest group (169 days, $44.59 \%$ ). In both cases, HH was identified as the smallest group (76 days, $20.05 \%$, in Israel; 10.8 , $15.88 \%$, in Hong Kong).

\section{Analysis of Allocation Patterns}

The larger sample size and wealth of information allowed an in-depth exploration of the factors that lead to the emergence of the identified clusters, an analysis not carried for the Hong Kong case study. Thus, several variables that could affect the choice of time-space pattern were selected for the analysis (Table 4). These variables were used in a multinomial regression model studying their effects on cluster membership. While this analysis did not rely on the common conceptualization of such models as a method representing utility-maximizing choices, we do borrow here some of its notation in order to examine the role of each variable. The multinomial logistic model relies on a definition of a linear function of the form $Y=\beta x+\alpha$. Traditionally, a differentiation between individual-specific and alternative-specific variables is made. Following the different perspectives on elements motivating tourists' behavior, we suggest here a different, two-level, classification: according to the behavioral dimension (external elements, timespace, cognitive, emotional-cultural) and to the relevant temporal unit (visit day, entire visit). Thus, it possible to identify eight types of variables, the variables used in the current analysis representing six of those (Table 4).

The multinomial regression used the time-maximizing behavioral pattern (HL) as the baseline category, thus allowing us to explore which variables induced a more space-oriented behavioral pattern. Since religion data was not available for every participant, thus reducing sample sizes, two models were estimated - one not using this variable and one with it, so as to estimate the robustness of effects. The main interesting result from these models (Table 5, models 1 and 2) is that the specific destination has a consistent effect on behavioral patterns. A second stage of analysis was thus carried, where the two models were estimated for each city separately (with and without religion; Jerusalem: models 3 and 4, Tel-Aviv: 5 and 6) (see Table 5).

\section{Interpretation of Results}

Several interesting findings emerge in Table 5. First, the only variable that remains significant regardless of the type of model is transport mode, where private vehicle-based transport seems to encourage the use of the more spatially explorative behavioral strategies. Other than that, all other effects that were identified in models 1 and 2 either proved to be destination-specific or became insignificant. Some of the effects make intuitive sense:

- The effect of transport mode: it is possible to attribute the tendency away from the HL pattern, evident in the positive coefficient values over all models and groups, to the enhanced flexibility that tourists using private vehicle-based transport enjoy, thus adopting less time-focused strategies. 


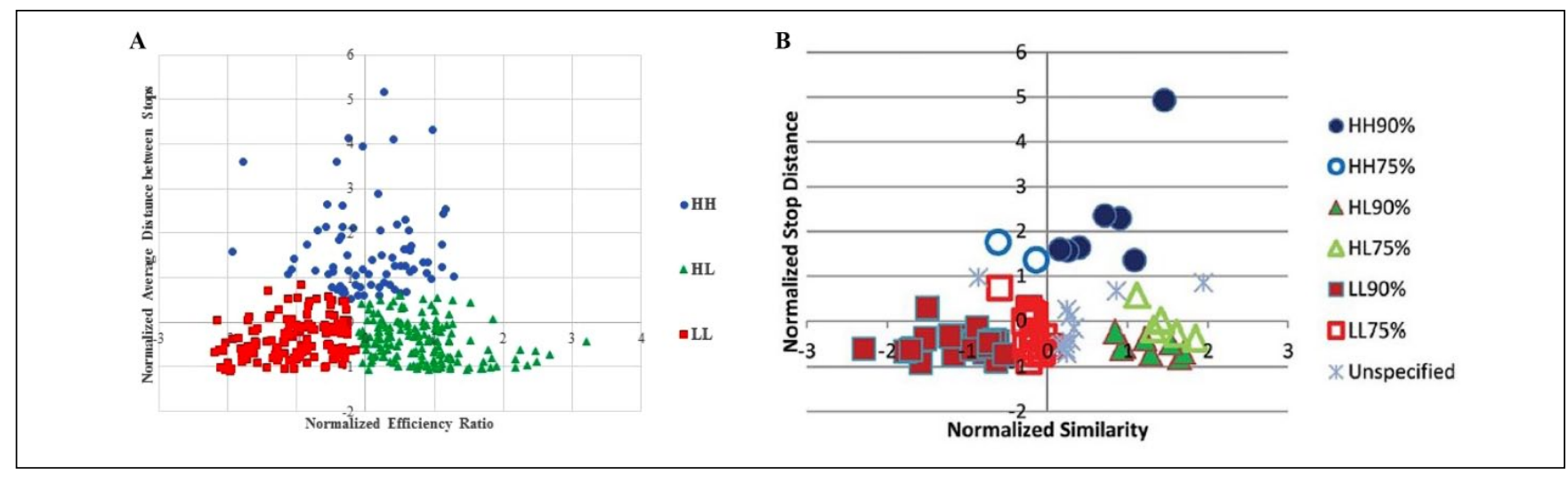

Figure 5. (A) Clustering results for Tel-Aviv and Jerusalem. (B) Clustering results for Hong Kong (source: Grinberger, Shoval, and McKercher 2014, Taylor and Francis Ltd: www.tandfonline.com).

Table 4. Analysis Variables, by Source of Information and Type.

\begin{tabular}{|c|c|c|c|}
\hline Variable Name & Details & Source & Classification \\
\hline Child & Binary variable: I if the visiting group includes children. & Questionnaire & Time-space, visit specific \\
\hline Senior & $\begin{array}{l}\text { Binary variable: I if the visiting group includes senior } \\
\text { citizens. }\end{array}$ & Questionnaire & Time-space, visit specific \\
\hline $\mathrm{H}$ distance & $\begin{array}{l}\text { Log value of hotel's distance from the touristic center } \\
\text { of the city (Jaffa gate in Jerusalem, beach in Tel-Aviv): } \\
\text { in days that did not start and end at the same place, } \\
\text { the computation used the closer of the two hotels }\end{array}$ & Processing of GPS data & Time-space, day specific \\
\hline Mode: private & Binary variable: I for days using private transport & Activity data & Time-space, day specific \\
\hline $\mathrm{H} 2$ distance & $\begin{array}{l}\text { Log value of distance from the city's touristic center } \\
\text { for the more distant hotel: calculated only for days } \\
\text { that did not start and end at the same location, } 0 \\
\text { otherwise }\end{array}$ & Processing of GPS data & Time-space, day specific \\
\hline Activity distance & $\begin{array}{l}\text { Log value of distance of the stop furthest away from } \\
\text { the city's touristic center: calculated only for days } \\
\text { that started and ended at the same location, yet } \\
\text { included activities outside the city; } 0 \text { otherwise }\end{array}$ & Processing of GPS data & Time-space, day specific \\
\hline Weekend & $\begin{array}{l}\text { Binary variable: I if visit was during a Friday or a } \\
\text { Saturday, } 0 \text { otherwise }\end{array}$ & Questionnaire & $\begin{array}{l}\text { External factors, day } \\
\text { specific }\end{array}$ \\
\hline Winter & $\begin{array}{l}\text { Binary variable: I if visit was during the months } \\
\text { November to March, } 0 \text { otherwise }\end{array}$ & Questionnaire & $\begin{array}{l}\text { External factors, visit } \\
\text { specific }\end{array}$ \\
\hline Visit length & Total number of days spent in the city & Processing of GPS data & Cognitive, visit specific \\
\hline Days left & $\begin{array}{l}\text { Visit length minus the number of previous visit days in } \\
\text { the city. }\end{array}$ & Processing of GPS data & Cognitive, visit specific \\
\hline First visit & $\begin{array}{l}\text { Binary variable: I for first-time visitors to Israel, } 0 \\
\text { otherwise. }\end{array}$ & Questionnaire & Cognitive, visit specific \\
\hline \multicolumn{4}{|l|}{ Purpose } \\
\hline $\begin{array}{l}\text { Family } \\
\text { Religion } \\
\text { Tourism }\end{array}$ & $\begin{array}{l}\text { Binary variables: I if the participant indicated this } \\
\text { purpose, } 0 \text { otherwise (No participants visiting for } \\
\text { business purposes were included in the final dataset. } \\
\text { The baseline category was "Other".) }\end{array}$ & Questionnaire & $\begin{array}{l}\text { Cultural-emotional, visit } \\
\text { specific }\end{array}$ \\
\hline \multicolumn{4}{|l|}{ Religion } \\
\hline $\begin{array}{l}\text { Jews, other } \\
\text { Jews, religious }\end{array}$ & $\begin{array}{l}\text { Binary variables: I if the participant indicated this } \\
\text { religious affiliation, } 0 \text { otherwise (This does not } \\
\text { include "Muslim" because the final sample did not } \\
\text { include Muslim tourists. The baseline category was } \\
\text { "Christian"; "Other" was treated as no data.) }\end{array}$ & Questionnaire & $\begin{array}{l}\text { Cultural-emotional, visit } \\
\text { specific }\end{array}$ \\
\hline City: Jerusalem & $\begin{array}{l}\text { Binary variable: I if visit day was in Jerusalem, } 0 \\
\text { otherwise }\end{array}$ & Processing of GPS data & $\begin{array}{l}\text { External factors, day } \\
\text { specific }\end{array}$ \\
\hline
\end{tabular}


Table 5. Multinomial Regression Analysis Results (Unstandardized Coefficients).

\begin{tabular}{|c|c|c|c|c|c|c|c|c|c|c|c|c|}
\hline & \multicolumn{2}{|c|}{ (I) } & \multicolumn{2}{|c|}{ (2) } & \multicolumn{2}{|c|}{ (3) } & \multicolumn{2}{|c|}{ (4) } & \multicolumn{2}{|c|}{ (5) } & \multicolumn{2}{|c|}{ (6) } \\
\hline & $\mathrm{HH}$ & LL & $\mathrm{HH}$ & LL & $\mathrm{HH}$ & LL & $\mathrm{HH}$ & LL & $\mathrm{HH}$ & LL & $\mathrm{HH}$ & LL \\
\hline Child & 0.14 & 0.35 & 0.13 & 0.24 & - & - & - & - & - & - & - & - \\
\hline Senior & 0.01 & 0.07 & $-0.96^{a}$ & -0.22 & -0.61 & 0.22 & $-0.98^{b}$ & 0.02 & 0.99 & -0.36 & 0.04 & -0.82 \\
\hline $\mathrm{H}$ distance & $-0.23^{a}$ & -0.18 & -0.24 & -0.17 & -0.21 & -0.29 & -0.35 & -0.28 & -0.20 & -0.16 & -0.17 & -0.14 \\
\hline Mode: private & $1.47^{c}$ & $0.97^{c}$ & $1.77^{c}$ & $1.12^{c}$ & $1.19^{\mathrm{b}}$ & $0.86^{b}$ & $1.67^{\mathrm{c}}$ & $1.04^{\mathrm{b}}$ & $2.34^{c}$ & $1.26^{\mathrm{c}}$ & $3.69^{\mathrm{c}}$ & $1.64^{c}$ \\
\hline $\mathrm{H} 2$ distance & $-0.08^{b}$ & $-0.06^{b}$ & $-0.09^{\mathrm{b}}$ & $-0.05^{a}$ & $-0.09^{a}$ & -0.03 & $-0.14^{b}$ & -0.03 & -0.07 & $-0.10^{\mathrm{b}}$ & -0.09 & $-0.11^{b}$ \\
\hline Activity distance & 0.08 & 0.01 & 0.07 & -0.01 & $0.16^{\mathrm{b}}$ & 0.05 & 0.15 & 0.03 & -0.04 & -0.05 & -0.04 & -0.09 \\
\hline Weekend & 0.04 & -0.00 & -0.13 & 0.03 & -0.33 & 0.02 & -0.88 & -0.02 & $0.92^{\mathrm{a}}$ & 0.02 & $1.20^{\mathrm{a}}$ & 0.26 \\
\hline Winter & 0.09 & 0.37 & -0.05 & $0.53^{\mathrm{a}}$ & -0.51 & 0.27 & -0.82 & 0.59 & 0.68 & 0.26 & 0.78 & 0.18 \\
\hline Visit length & 0.00 & -0.00 & 0.06 & 0.02 & 014 & 0.09 & 0.19 & 0.08 & -0.07 & -0.08 & -0.02 & -0.04 \\
\hline Days left & 0.00 & 0.00 & -0.02 & -0.01 & -0.03 & 0.01 & -0.11 & -0.03 & 0.11 & 0.02 & 0.21 & 0.10 \\
\hline First visit & $0.65^{a}$ & $0.61^{\mathrm{b}}$ & $1.10^{b}$ & $0.68^{a}$ & $1.57^{\mathrm{c}}$ & 0.73 & $3.38^{c}$ & $1.27^{\mathrm{b}}$ & -0.14 & 0.59 & -0.28 & 0.27 \\
\hline \multicolumn{13}{|l|}{ Purpose } \\
\hline Family & -0.21 & -0.10 & -0.16 & -0.27 & -0.81 & $-1.19^{b}$ & -0.77 & $-1.15^{b}$ & 0.42 & $0.74^{\mathrm{a}}$ & 0.73 & 0.90 \\
\hline Religion & 0.42 & 0.81 & 0.61 & 0.85 & -0.49 & 0.01 & -0.42 & 0.13 & $2.10^{\mathrm{a}}$ & $1.62^{\mathrm{a}}$ & $3.07^{\mathrm{b}}$ & $2.04^{a}$ \\
\hline Tourism & -0.12 & 0.04 & -0.13 & -0.12 & -0.07 & -0.41 & 0.05 & -0.34 & 0.20 & 0.35 & 0.42 & 0.13 \\
\hline \multicolumn{13}{|l|}{ Religion } \\
\hline Jews, other & - & - & $0.89^{\mathrm{a}}$ & 0.53 & - & - & $2.14^{\mathrm{b}}$ & $1.02^{\mathrm{a}}$ & - & - & 0.24 & -0.05 \\
\hline Jews, religious & - & - & 0.35 & -0.12 & - & - & $2.0 I^{\mathrm{b}}$ & 0.43 & - & - & -0.28 & -0.90 \\
\hline City: Jerusalem & $0.78^{b}$ & $0.86^{c}$ & $0.80^{\mathrm{b}}$ & $1.05^{c}$ & - & - & - & - & - & - & - & - \\
\hline $\mathrm{N}$ & \multicolumn{2}{|c|}{374} & \multicolumn{2}{|c|}{286} & \multicolumn{2}{|c|}{184} & \multicolumn{2}{|c|}{156} & \multicolumn{2}{|c|}{190} & \multicolumn{2}{|c|}{130} \\
\hline$p$ value & \multicolumn{2}{|c|}{0.003} & \multicolumn{2}{|c|}{0.006} & \multicolumn{2}{|c|}{0.017} & \multicolumn{2}{|c|}{0.002} & \multicolumn{2}{|c|}{0.005} & \multicolumn{2}{|c|}{0.027} \\
\hline
\end{tabular}

Note: Models (I) and (2): entire sample; models (3) and (4): activity days in Jerusalem; models (5) and (6): activity days in Tel-Aviv. Significant values are in bold.

${ }^{a} \mathrm{p}<0.10,{ }^{b} \mathrm{p}<0.05,{ }^{c} \mathrm{p}<0.01$.

- The effects of elderly members of the visiting group: the negative coefficient values for the HH pattern in Jerusalem (models 3 and 4), which represent these groups' tendency to avoid that pattern in Jerusalem, could be related to the topographical structure of the city and its effects on mobility, along with the more dispersed distribution of activities.

- The effects of visiting friends and relatives: it is possible to attribute the tendency toward more focused visits (HL) in Jerusalem, visible in the significantly negative coefficient values for the LL pattern in models 3 and 4, to these tourists having a local guiding them through the city.

- The "furthest" hotel effect: allocating time to movement between destinations reduces the amount of time available for activity, thus encouraging tourists to adopt more time-efficient strategies. In Tel-Aviv, where sites are more adjacent to each other and mobility between them is easier, this leads to a significant decrease in the implementation of the more spatially constrained LL strategy, as evident in the negative coefficient values in models 5 and 6. In Jerusalem, where movement between sites is carried over longer distances, the coefficients for the HH pattern are significantly negative (models 3 and 4), meaning its application becomes less probable.
- Weekend effect in Tel-Aviv: in Israel, many venues close down during the Sabbath (the time period between Friday afternoon and Saturday evening). While in Tel-Aviv this is less common, main sites like the Carmel and Flea markets, stores in Neve Tzedek, or museums are closed or limit their opening hours during this time. This breaks the northsouth continuum of sites in which distances between sites are relatively small, thus driving tourists toward a more dispersed $\mathrm{HH}$ pattern (seen in the positive coefficient values in models 5 and 6 for this behavioral pattern).

In contrast to these effects, the interpretation of other effects requires a more in-depth analysis of the behavior of subpopulations. For instance, the differentiating effect of previous visits between the cities, where the coefficients in Jerusalem are almost always positive and significant while in Tel-Aviv no significant effect is registered, can be better understood only when the population is divided by the number of previous visits, and each subpopulation's spatial patterns are explored (Figure 6A-D). Previous research has shown that repeat visitors present more concentrated visit patterns than first-time visitors (McKercher et al. 2012). This is the picture that rises in Jerusalem where the activities of repeat visitors are concentrated on the route between the city 

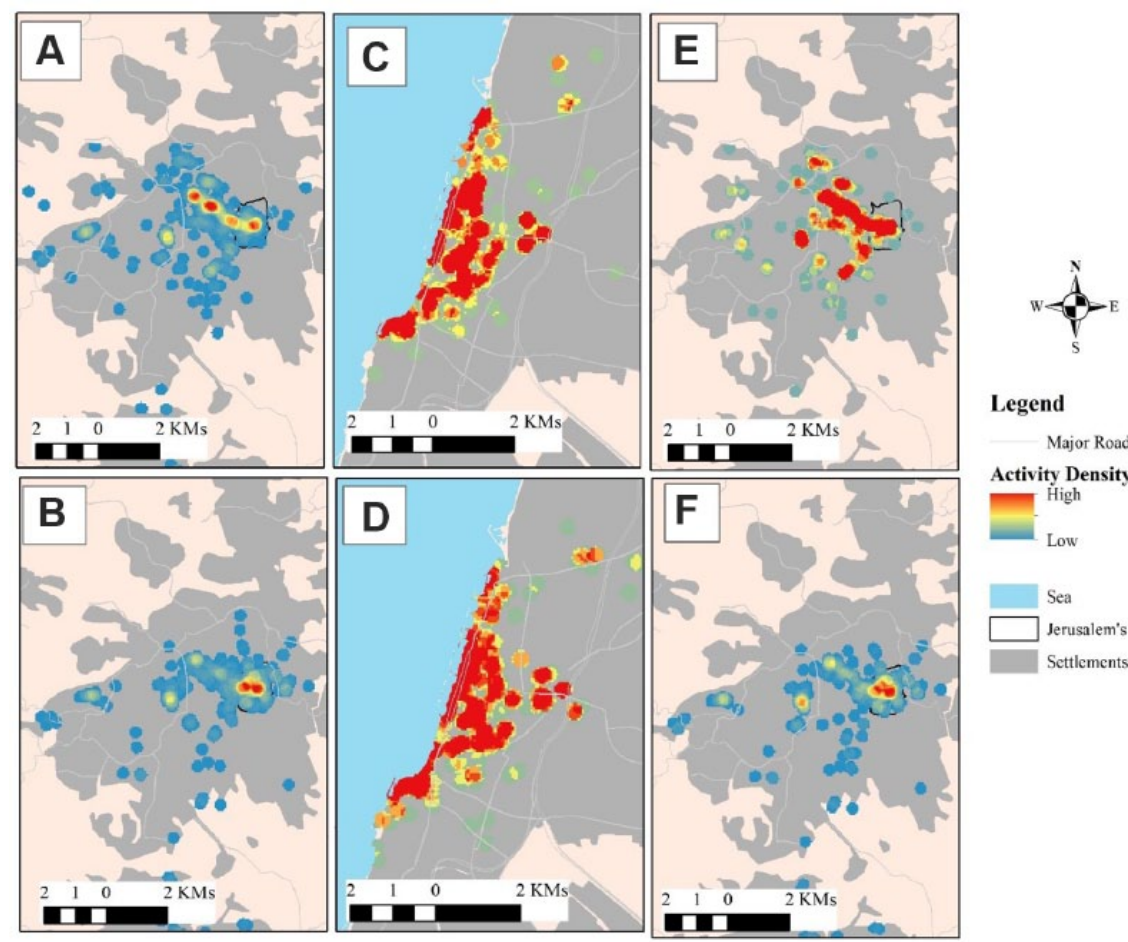

Legend

Major Roads

Activity Density

High

Low

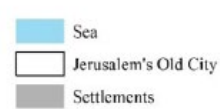

Figure 6. Activity densities for different subpopulations: $(A)$ repeat visitors in Jerusalem, $(B)$ first-time visitors in Jerusalem, $(C)$ repeat visitors in Tel-Aviv, (D) first-time visitors in Tel-Aviv, (E) Jewish (religious and other) visitors in Jerusalem, (F) Christian visitors in Jerusalem.

center and the Old City, while first-time visitors show more dispersed patterns, with the Old City being the sole anchor. In Tel-Aviv, however, no real difference is evident. It is possible to attribute these patterns to the organizing role of the Old City in Jerusalem - being the most dominant "must-see" area of the city - which leads returning visitors in the city to focus on it and on the path leading to it, thus creating HL kind of patterns. In Tel-Aviv, no such dominant sites exist (at least not as salient as the Old City), thus enabling more explorative behaviors even for repeat visitors.

The saliency of the Old City also explains the positive coefficient values of Jewish religious affiliation for the $\mathrm{HH}$ pattern in Jerusalem. While the sites in the Old City are the most attractive for both Jewish and Christian tourists, Jewish visitors are more likely to find several other sites to be important or interesting (e.g., Mea She'arim, Yemin Moshe, the City of David). It is thus not surprising to see that their visit more frequently included these sites (Figure $6 \mathrm{E}$ ), thus encouraging $\mathrm{HH}$ behaviors. As the Old City is the only organizing element for Christian visitors, their visit patterns outside of it were dispersed (Figure 6F), enabling the implementation of other strategies.

The role of the Old City affects not only visit patterns within Jerusalem but also the entire visit to Israel. This is the factor behind a seemingly odd finding - the change in behavioral patterns in Tel-Aviv found for tourists visiting for religious purposes (evident in significant coefficient values for this variable in models 5 and 6 ). Why should religiously oriented individuals change their behavior in a secular city? A possible explanation lies in the perception of Jerusalem as a more central destination within Israel, consequently attracting more visit days and affecting the amount of time available for visiting other locations, including Tel-Aviv. Religiously oriented visitors may thus decide either to skip Tel-Aviv entirely, or to limit their visiting time in it. The latter group may try to compensate for this lack of time by adopting more space-oriented strategies (HH, LL) in TelAviv. To verify this argument, we carried a multivariate Tobit regression (Huang, Sloan, and Adamache 1987; estimated using the mvtobit model in Stata 13.0; Barslund 2015), allowing us to determine the effect of religious activity on the number of visit days in both Tel-Aviv and Jerusalem. This model was chosen since visit length is a censored variable (lower limit of zero) and since the values of dependent variables are determined simultaneously (increasing the number of days in Jerusalem is expected to decrease the duration of visit in Tel-Aviv and vice versa). To control for mediating influences, additional variables were included in the model. The results (Table 6) confirm the hypothesis, showing that the two variables are negatively correlated (correlation value of -0.68), and that visit for religious purposes negatively affects the length of visit in Tel-Aviv (coefficient 
Table 6. Multivariate Tobit Model Estimation Results (Unstandardized Coefficients).

\begin{tabular}{|c|c|c|}
\hline & Jerusalem & Tel-Aviv \\
\hline First visit & $-1.39^{b}$ & 0.83 \\
\hline Total duration of visit to Israel & $0.44^{c}$ & $0.27^{c}$ \\
\hline $\begin{array}{l}\text { Religion } \\
\text { Jews: other }\end{array}$ & $-1.19^{a}$ & 0.49 \\
\hline Jews: religious & $1.97^{\mathrm{b}}$ & $-3.03^{c}$ \\
\hline Winter & -0.25 & 0.10 \\
\hline Purpose & -0.64 & -0.16 \\
\hline Family and friends & & \\
\hline Religion & 1.42 & $-1.95^{b}$ \\
\hline Tourism & 0.29 & 0.22 \\
\hline$\sigma$ & $3.38^{c}$ & $3.30^{c}$ \\
\hline $\begin{array}{l}\text { Correlation }(\rho) \text { between endogenous } \\
\text { variables }\end{array}$ & \multicolumn{2}{|l|}{$-0.68^{c}$} \\
\hline $\mathrm{N}$ & \multicolumn{2}{|c|}{214} \\
\hline Log likelihood & \multicolumn{2}{|l|}{$-903.99^{c}$} \\
\hline
\end{tabular}

Note: Bold values indicate statistical significance.

${ }^{a} p<0.10,{ }^{b} p<0.05,{ }^{c} p<0.01$.

value of -1.95). Other results, such as the shorter visit in Jerusalem for first-time visitors, the positive effect of total visit duration, and the effects of religious affiliation also make sense.

\section{Discussion and Conclusion}

This article presents an analysis of the factors behind the emergence of tourists' observed visit patterns in the cities of Jerusalem and Tel-Aviv, Israel. The analysis included characterizing tourists' daily activity trajectories, derived from high-resolution GPS traces data, according to preferences regarding the allocation of time-space resources they reflect. Trajectories were clustered into three unique behavioral patterns, each reflecting a different reaction to the inherent tension between the consumption of time and space resources. The factors leading to the emergence of these patterns were studied via the analysis of the effect of individual-, day-, and destination-specific variables along the emotional-cultural, time-geographic, and cognitive dimensions.

The results point to the complex interrelationships between these dimensions and the unique spatial conditions at the destination, as most of the identified effects were valid only within one specific spatial context. In fact, only two results were replicated regardless of which subset of the data was used to investigate behavior (Jerusalem, Tel-Aviv, or the entire data set): no LH cluster being identified (which also replicates previous results from Hong Kong; Grinberger, Shoval, and McKercher 2014), and an increased tendency to choose the LL or HH patterns when using private vehiclebased transport. The different clusters represent the participants' choice patterns in reaction to the constraints of reality, a process that is cognitive in nature. Thus, it is possible to interpret the repeating tendency to avoid the space-maximizing LH pattern as resulting from a cognitive overvaluation of the time resource. In this context, it is also possible to explain the effect of transport mode as another cognitive reaction to space-time constraints: the increase in the size of accessible space derived from the use of private transport seems to encourage a less stressful approach toward the time resource, thus leading to the adoption of more space-oriented approaches (LL or $\mathrm{HH}$ ) at the expense of the most time-efficient one (HL). Thus, these primary effects seem to reflect more generic cognitive biases than responses to the timespace realities of the choice situation.

All other identified effects displayed time-space dependencies related to the morphology of the destination and to the distribution of activities within it. Yet, except maybe for the "furthest hotel" effect (in which reduction in time available for visiting the city is interacted with spatial structure), these effects seem to be very much dependent on the specific cultural, social, cognitive, and precognitive decision-making contexts. For instance, the destinations' morphology may be used to explain the findings regarding the effects of number of previous visits to Israel, religious affiliation, and day in the week (weekend or not) on behavior. According to Lynch's seminal findings (1960) on how individuals perceive their urban environments, the distribution of activities is sufficient for creating a cognitive effect on behavior: in Jerusalem, the Old City may act as an organizing "district," while in TelAviv the north-south continuum parallel to the coast can be viewed as a linear "path." Yet, as behavior varied in relation to the religious affiliation variable, an element that is cultural/emotional in nature, understanding this finding as representing a purely spatiotemporal-cognitive effect is incorrect. The precognitive (emotional) or metacognitive (cultural) salience, or lack of it, of different sites is the one that probably guided choices in this case.

This dimension seemed to operate at even deeper levels, as the purpose of visit determined the amount of attention (i.e., visit duration) given to each city. This cultural/affectual effect leads to a cognitive one in Tel-Aviv where the scarcity of the time resource (i.e., shorter visit durations) alters behavioral decisions. These decisions also seem to be socially distributed, as the company of the individual affects behavior, as evident in the effects of visiting groups with oldage members or for tourists visiting friends and family. The variance of effects in terms of significance and sign between the cities again suggests that these effects are dependent upon spatial context.

The main contribution of these findings lies in them uncovering the complexity of the procedure through which visit patterns emerge. The roles of different decision-making dimensions change with scale, place, and individual, while the time-space dimension is intertwined through all decision-making processes, when they are carried in situ. Accordingly, this dimension always interacts with other dimensions, where cognitive and precognitive dimensions 
both exert an in situ effect and guide choice stages that precede the actual activity (such as the effect of visit for religious purposes on visit length in each city). This contribution, beyond adding to the theoretical knowledge, also holds practical implications for design and marketing efforts. For example, it answers the need for a better understanding of the behavioral basis of tourism, as identified within the literature discussing the application of information technologies to assist and guide tourists during their visit (Gretzel 2011; Gretzel, Hwang, and Fesenmaier 2012). This discussion stresses the decision-making context as a critical factor in the design of mobile environments for tourists (Lamsfus et al. 2011, 2012). The results here show that context is an always-evolving concept rather than a static one, thus suggesting that context-aware information applications for tourism need to be designed with flexibility in mind, similar to the view suggested by Lamsfus and his colleagues (2015).

Therefore, it is not advisable to think of decision making as a linear, one-dimensional sequence of events that consists of distinct stages at which each behavioral component has a unique influence. Instead, as proposed by McCormack and Schwanen (2011), the decision is better described as a multidimensional space-time in which complex relationships between different behavioral components exist over multiple spatial scales and temporal instances, in ways that "complicate a neat linearity between past, present, and future" (McCormack and Schwanen 2011, p. 2808). The results here support this view, as well as some of the propositions these authors make regarding the nature of decision based on this conceptualization: the effects of personal characteristics show that the decision is differentiated and experienced differently by different individuals; the effects of group members and social-cultural components point to the decision as socially distributed; and the dependence of many of the effects on the time-space realities (physical and others) exposes the decision to be contextually related. As such, the results here unravel the space-times through which tourists' behaviors unfold, thus enriching the conceptual and empirical base for the study of intra- and interdestination timespace behaviors.

A second contribution of this article is of a more methodological or conceptual nature. Tourism and spatial behavior studies increasingly use high-resolution mobility in recent years (Shoval and Ahas 2016). While such data is indeed rich in the spatiotemporal sense, it generally lacks when other behavioral dimensions are considered. Recently, several studies have shown how such data can be used to gain knowledge on individuals' and populations' cognitive images of space (Manley 2016; Manley, Addison, and Cheng 2015). Such works join previous tourism-related findings on the effect of time-space elements or knowledge on behavior (McKercher et al. 2012; Shoval et al. 2011). The analysis carried out here presents an example of how the intertwined effects of these and other dimensions can be exposed using large mobility data sets. It thus answers a need in this age of data abundance (Chen et al. 2016), suggesting that even without extensive exploration of each individual's internal world, it is still possible to gather behavioral insights. This is not to say that such studies of the individual are redundant. In fact, we agree here with Chen and colleagues (2016) and suggest that future research aiming to expand our understanding of behavioral processes must rely on the development of large-scale analysis techniques along with in-depth investigations of individuals' motives. Such joint efforts would serve to indicate how time-spaces, personal characteristics, and social-cultural contexts intermingle to generate spatiotemporal behavior patterns. The new knowledge gained in such a way would not only enrich theoretical thinking but would also lead the way for the design of better management tools for urban tourism.

\section{Appendix A}

\section{Outlier Identification}

The aim of this procedure is to identify inaccurate samples, in the form of outliers, and remove them from the database. An outlier trace was identified if its momentary speed value (i.e., the speed as derived based on the difference in location and time between this trace and the previous one) exceeded $250 \mathrm{~km} / \mathrm{h}$ or when all the following conditions were true:

$$
\begin{gathered}
A c c_{i}>0 \\
A c c_{i}>{\overline{A c c_{\text {neigh }-}}}+5^{*} A c c_{\text {neigh }, \sigma} \\
\text { Speed }_{i}>\text { Speed }_{\text {neigh }, \text { median }}+5^{*} \text { Per }_{10 . \text { speed }, \text { neigh }+}
\end{gathered}
$$

where:

$A c c_{i}$ is the momentary acceleration for sample $i$ (i.e., the change in momentary speed, relative to sample $i-1$ ),

$n e i g h-$ relates to the 10 samples preceding $i$,

$n e i g h+$ relates to the 10 samples following $i$,

$\overline{A C C}_{\text {set }}$ is the average acceleration over a given set of traces,

$A c c_{s e t, \sigma}$ is the standard deviation value for momentary acceleration over a given set of traces,

Speed $_{i}$ is the momentary speed for sample $i$,

Speed $_{\text {set,median }}$ is the median value of momentary speed over a given set of traces,

$\mathrm{Per}_{j, \text { speed,set }}$ is the $j$ th percentile speed value over a given set of traces.

These definitions rely on the assumption that outliers are samples that present a sudden shift in location that does not match the nature movement over previous or subsequent periods. From this, it follows that outliers must have a positive acceleration value. To avoid the false 
identification of mode or behavior-type change instances as outliers (e.g., from stop to movement, transport mode changes), each sample was compared to acceleration values of previous samples and the speed values of the following ones. As speed is a censored variable, the procedure uses medians and percentile values instead of averages and standard deviations.

\section{Appendix B}

\section{Activity-Stop Matching Procedure}

GPS-based stops were matched with report-based activities by computing a time-space overlap score for each stopactivity pair as follows:

$$
\begin{gathered}
T S_{s, a}=\frac{\min \left(s_{\text {end }}, a_{\text {end }}\right)-\max \left(s_{\text {start }}, a_{\text {start }}\right)}{s_{\text {duration }}} \\
S S_{s, a}=1-\log \Phi_{s_{\mu}, s_{\sigma}}(d s, a) \\
M S_{s, a}=\frac{T S_{s, a}+S S_{s, a}}{2}
\end{gathered}
$$

where:

$\mathrm{TS}_{s, a}$ is the temporal overlap score for activity $a$ and stop $s$, $s_{\text {star }} a_{\text {start }}$ are the beginning times for activity $a$ and stop $s$,

$s_{\text {end }}, a_{\text {end }}$ are the end times for activity $a$ and stop $s$,

$s_{\text {duration }}$ is the duration of stop $s$ in seconds,

$S S_{s, a}$ is the spatial overlap score,

$\log \Phi_{\mu, \sigma}(x)$ is the cumulative $\log$-normal probability for obtaining $x$ given parameters $\mu$ and $\sigma$,

$s_{\mu}$ is the average distance between the samples that belong to stop $s$ and their mean center (i.e., $s$ 's coordinates),

$s_{\sigma}$ is the standard deviation for the above distances,

$d_{s, a}$ is the Euclidean distance between stop $s$ and activity $a$, $M S_{s, a}$ is the spatiotemporal overlap score.

These scores can be interpreted as the temporal overlap between a stop and an activity $\left(T S_{s, a}\right)$ and the probability that the identified location of the activity is within the sampling error margins of the stop $\left(S S_{s, a}\right)$. When the stop and the activity entirely overlap temporally (i.e., $s_{\text {start }}=a_{\text {start }}$ and $s_{\text {end }}$ $\left.=a_{\text {end }}\right) T S_{s, a}$ is 1 , and 0 when no overlap is recorded. $S S_{s, a}$, being a probability score, also ranges from 0 to 1 . Consequently, $M S_{s, a}$, the average of both scores, also ranges from 0 to 1 . Overlap values of 0.5 or above were defined to identify valid matches as they indicate that both $S S_{s, a}$ and $T S_{s, a}$ must be larger than 0 , meaning some level of both temporal and spatial correlation exists.

\section{Acknowledgments}

The authors would like to thank the Jerusalem Transport Master Plan Team for providing the data, and to Mr. Muli Yehezkel from MPayer for his support.

\section{Declaration of Conflicting Interests}

The author(s) declared no potential conflicts of interest with respect to the research, authorship, and/or publication of this article.

\section{Funding}

The author(s) received no financial support for the research, authorship, and/or publication of this article.

\section{Notes}

1. It is incorrect to compare the characteristics of the valid subsample with those of the entire population, as they do not make independent samples. The significance of differences was thus verified by comparison to the nonvalid subsample.

2. Density surfaces (created here using ESRI ArcMap's Point Density Tool) are continuous visualizations of the concentration of a discrete spatial phenomenon. Computing them requires dividing the area into cells of fixed size ( $50 \mathrm{sq} \mathrm{m}$ here) and then computing density values near each cell (based on a predefined radius, $200 \mathrm{~m}$ here).

3. In the Hong Kong case, a fuzzy cluster membership criterion was employed, thus producing results that vary by the iteration of the procedure. The results present groups' characteristics, such as size, averaged over the entire set of results.

\section{References}

Archer, Brian, Chris Cooper, and Lisa Ruhanen. 2005. "The Positive and Negative Impacts of Tourism." In Global Tourism, 3rd ed., edited by William F. Theobald, 79-102. London: Elsevier Butterworth Heinmann.

Barslund, Mikkel. 2015. "MVTOBIT: Stata Module to Calculate Multivariate Tobit Models by Simulated Maximum Likelihood (SML)."https://EconPapers.repec.org/RePEc:boc:bocode:s456875.

Bauder, Michael, and Tim Freytag. 2015. "Visitor Mobility in the City and the Effects of Travel Preparation." Tourism Geographies 17 (5): 682-700.

Bermingham, Luke, and Ickjai Lee. 2014. "Spatio-temporal Sequential Pattern Mining for Tourism Sciences." Procedia Computer Science 29:379-89.

Bigné, J. Enrique, and Luisa Andreu. 2004. "Emotions in Segmentation: An Empirical Study." Annals of Tourism Research 31 (3): 682-96.

Bowden, Jiaolan. 2003. “A Cross-national Analysis of International Tourists Flows in China." Tourism Geographies 5 (3): 257-79.

Brunyé, Tad T., Caroline R. Mahoney, and Holly A. Taylor. 2015. "Paths with More Turns Are Perceived as Longer: Misperceptions with Map-Based and Abstracted Path Stimuli." Perceptual and Motor Skills 120 (2): 438-61.

Butler, R. W. 1980. "The Concept of a Tourist Area Cycle of Evolution: Implications for Management of Resources." Canadian Geographer 24 (1): 5-12.

Cadwallader, Martin. 1975. "A Behavioral Model of Consumer Spatial Decision Making." Economic Geography 51 (4): 339-49.

Chang, Hsuan Hsuan. 2015. "Which One Helps Tourists Most? Perspective of International Tourists Using Different Navigation Aids." Tourism Management 17 (3): 350-69.

Chen, Cynthia, Jingtao Ma, Yusak Susilo, Yu Liu, and Menglin Wang. 2016. "The Promises of Big Data and Small Data for Travel Behavior (aka Human Mobility) Analysis." 
Transportation Research Part C: Emerging Technologies 68:285-89.

Couclelis, H., R. G. Golledge, N. Gale, and W. Tobler. 1987. "Exploring the Anchor-Point Hypothesis of Spatial Cognition." Journal of Environmental Psychology 7 (2): 99-122.

Correia, Antónia, and Metin Kozak. 2017. "The Review Process in Tourism Academia: An Elaboration of Reviewers' Extrinsic and Intrinsic Motivations." Journal of Hospitality and Tourism Management 32:1-11.

De Cantis, Stefano, Mauro Ferrante, Alon Kahani, and Noam Shoval. 2016. "Cruise Passengers' Behavior at the Destination: Investigation Using GPS Technology." Tourism Management 52:133-50.

Dejbakhsh, Sabereh, Colin Arrowsmith, and Merv Jackson. 2011. "Cultural Influence on Spatial Behavior." Tourism Geographies 13 (1): 91-111.

Downs, Roger M., and David Stea. 1973. "Cognitive Maps and Spatial Behavior: Process and Products." In Image and Environment, edited by Roger M. Downs and David Stea, 826. Chicago: Aldine.

D’Urso, Pierpaolo, and Riccardo Massari. 2013. "Fuzzy Clustering of Human Activity Patterns." Fuzzy Sets and Systems 215:29-54.

Ellegård, Kajsa, and Uno Svedin. 2012. "Torsten Hägerstraand's TimeGeography as the Cradle of the Activity Approach in Transport Geography." Journal of Transport Geography 23:17-25.

Fridgen, Joseph D. 1984. "Environmental Psychology and Tourism." Annals of Tourism Research 11 (1): 19-39.

Fridgen, Joseph D. 1987. "Use of cognitive maps to determine perceived tourism regions." Leisure Sciences 9 (2): 101-17.

Golledge, Reginald G. 2008. "Behavioral Geography and the Theoretical/Quantitative Revolution." Geographical Analysis 40 (3): 239-57.

Golledge, Reginald G., and Robert J. Stimson. 1997. Spatial Behavior: A Geographic Perspective. New York: Guilford.

Gong, Lei, Takayuki Morikawa, Toshiyuki Yamamoto, and Hitomi Sato. 2014. "Deriving Personal Trip Data from GPS Data: A Literature Review on the Existing Methodologies." ProcediaSocial and Behavioral Sciences 138:557-65.

Greenberg Raanan, Malka, and Noam Shoval. 2014. "Mental Maps Compared to Actual Spatial Behavior Using GPS Data: A New Method for Investigating Segregation in Cities." Cities 36:28-40.

Gretzel, Ulrike. 2011. "Intelligent Systems in Tourism: A Social Science Perspective." Annals of Tourism Research 38 (3): 757-79.

Gretzel, Ulrike, Yeong-Hyeon Hwang, and Daniel R. Fesenmaier. 2012. "Informing Destination Recommender Systems Design and Evaluation through Quantitative Research." International Journal of Culture, Tourism, and Hospitality Research 6 (4): 297-315.

Grinberger, A. Yair, Noam Shoval, and Bob McKercher. 2014. "Typologies of Tourists' Time-Space Consumption: A New Approach Using GPS Data and GIS Tools." Tourism Geographies 16 (1): 105-23.

Guy, Bonnie S., W. W. Curtis, and J. C. Crotts. 1990. "Environmental Learning of First-Time Travelers." Annals of Tourism Research 17:419-31.

Hägerstraand, Torsten. 1970. "What about People in Regional Science?" Papers of the Regional Science Association 24 (1): $7-21$.
Hallo, Jeffery C., J. Adam Becco, Cari Goetcheus, John McGee, Nancy Gard McGehee, and William C. Norman. 2012. "GPS as a Method for Assessing Spatial and Temporal Use Distributions of Nature-Based Tourists." Journal of Travel Research 51 (5): 591-606.

Huang, Cliff J., Frank A. Sloan, and Killard W. Adamache. 1987. "Estimation of Seemingly Unrelated Tobit Regressions via the EM Algorithm." Journal of Business and Economic Statistics 5 (4): 425-30.

Hwang, Yeong-Hyeon, and Daniel R. Fesenmaier. 2003. "Multidestination Pleasure Travel: Empirical Evidence from the American Travek Survey." Journal of Travel Research 42 (2): 166-71.

Hwang, Yeong-Hyeon, Ulrike Gretzel, and Daniel R. Fesenmaier. 2006. "Multicity Trip Patterns. Tourists to the United States." Annals of Tourism Research 33 (4): 1057-78.

Kahneman, Daniel, and Amos Tversky. 1979. "Prospect Theory: An Analysis of Decision under Risk.” Econometrica 47 (2): 263-92.

Kim, Seong-Il, and Daniel R. Fesenmaier. 1990. "Evaluating Spatial Structure Effects in Recreation Travel." Leisure Sciences 12 (4): 367-81.

Kitchin, Robert M. 1994. "Cognitive Maps: What Are They and Why Study Them?” Journal of Environmental Psychology 14 (1): 1-19.

Kwan, Mei-Po. 1999. "Gender, the Home-Work Link, and SpaceTime Patterns of Nonemployment Activities." Economic Geography 75 (4): 370-94.

Lamsfus, Carlos, Aurkene Alzua-Sorzabal, David Martín, and Emilio Torres. 2011. "Semantic-Based Modeling in Tourism." Information Technology \& Tourism 13 (4): 309-25.

Lamsfus, Carlos, David Martín, Aurkene Alzua-Sorzabal, Diego López-de-Ipiña, and Emilio Torres-Manzanera. 2012. "Context-Based Tourism Information Filtering with a Semantic Rule Engine.” Sensors 12 (5): 5273-89.

Lamsfus, Carlos, Dan Wang, Aurkene Alzua-Sorzabal, and Zheng Xiang. 2015. "Going Mobile: Defining Context for On-the-Go Travelers.” Journal of Travel Research 54 (6): 691-701.

Lenntorp, Bo. 1976. Paths in Time-Space Environments: A Time-Geographic Study of Movement Possibilities of Individuals. Lund: Royal University of Lund, Department of Geography.

Long, Jed A., and Trisalyn A. Nelson. 2013. "A Review of Quantitative Methods for Movement Data." International Journal of Geographical Information Science 27 (2): 292-318.

Long, Jed, and Trisalyn Nelson. 2015. "Home Range and Habitat Analysis Using Dynamic Time Geography." Journal of Wildlife Management 79 (3): 481-90.

Lue, Chi-Chuan, John L. Crompton, and Daniel R. Fesenmaier. 1993. "Conceptualization of Multi-destination Pleasure Trips." Annals of Tourism Research 20:289-301.

Lynch, Kevin. 1960. The Image of the City. Cambridge, MA: MIT press.

Manley, , Ed. 2016. "Estimating the Topological Structure of Driver Spatial Knowledge." Applied Spatial Analysis and Policy 9 (2): 165-89.

Manley, E. J., J. D. Addison, and T. Cheng. 2015. "Shortest Path or Anchor-Based Route Choice: A Large-Scale Empirical Analysis of Minicab Routing in London." Journal of Transport Geography 43:123-39. 
Massara, Francesco, and Fabio Severino. 2013. "Psychological Distance in the Heritage Experience." Annals of Tourism Research 42:108-29.

Mayer, Marius, Martin Müller, Manuel Woltering, Julius Arnegger, and Hubert Job. 2010. "The Economic Impact of Tourism in Six German National Parks." Landscape and Urban Planning 97 (2): 73-82.

McCormack, Derek P., and Tim Schwanen. 2011. "Guest Editorial: The Space-Times of Decision Making." Environment and Planning A 43 (12): 2801-18.

McKercher, Bob, Noam Shoval, Erica Ng, and Amit Birenboim. 2012. "First and Repeat Visitor Behaviour: GPS Tracking and GIS Analysis in Hong Kong." Tourism Geographies 14 (1): 147-61.

McKercher, Bob, Noam Shoval, Eerang Park, and Alon Kahani. 2015. "The [Limited] Impact of Weather on Tourist Behavior in an Urban Destination." Journal of Travel Research 54 (4): $442-55$.

McQueen, J. 1967. "Some Methods for Classification and Analysis of Multivariate Observations." In Proceedings of the Fifth Berkley Symposium on Mathematical Statistics and Probability, edited by L. M. le Cam and J. Neyman, 281-97. Berkley: University of California Press.

McQuoid, Julia, and Martin Dijst. 2012. "Bringing Emotions to Time Geography: The Case of Mobilities of Poverty." Journal of Transport Geography 23:26-34.

Miller, Harvey J. 1991. "Modeling Accessibility Using Space-Time Prism Concepts within Geographical Information Systems." International Journal of Geographical Information Systems 5 (3): 287-301.

Nanni, Mirco, and Dino Pedreschi. 2006. "Time-Focused Clustering of Moving Objects." Journal of Intelligent Information Systems 27 (3): 267-89.

Neutens, Tijs, Tim Schwanen, and Frank Witlox. 2011. "The Prism of Everyday Life: Towards a New Research Agenda for Time Geography." Transport Reviews 31 (1): 25-47.

Pearce, Philip L. 1977. "Mental Souvenirs: A Study of Tourists and Their City Maps.” Australian Journal of Psychology 29 (3): 203-10.

Pile, Steve. 2010. "Emotions and Affect in Recent Human Geography." Transactions of the Institute of British Geographers 35 (1): 5-20.

Pred, Allan. 1977. "The Choreography of Everyday Existence: Comments on Hägerstrand's Time-Geography and Its Usefulness." Economic Geography 53 (2): 207-21.

Renso, Chiara, Miriam Baglioni, Jose António F. de Macedo, Robert Trasarti, and Monica Wachowicz. 2013. "How You Move Reveals Who You Are: Understanding Human Behavior by Analyzing Trajectory Data." Knowledge and Information Systems 37 (2): 331-62.

Richardson, Anthony E., Daniel R. Montello, and Mary Hegarty. 1999. "Spatial Knowledge Acquisition from Maps and from Navigation in Real and Virtual Environments." Memory \& Cognition 27 (4): 741-50.

San Martín, Héctor, and Ignacio A. Rodríguez del Bosque. 2008. "Exploring the Cognitive-Affective Nature of Destination Image and the Role of Psychological Factors in Its Formation." Tourism Management 29 (2): 263-77.

Sarmento, João. 2017. "Tourists' Walking Rhythms: 'Doing' the Tunis Medina, Tunisia." Social \& Cultural Geography 18 (3): 295-314.
Schuessler, Nadine, and Kay Axhausen. 2009. "Processing Raw Data from Global Positioning Systems without Additional Information." Transportation Research Record: Journal of the Transportation Research Board 2015:28-36.

Shoval, Noam, and Rein Ahas. 2016. "The Use of Tracking Technologies in Tourism Research: The First Decade." Tourism Geographies 18 (5): 587-606.

Shoval, Noam, and Michal Isaacson. 2007a. "Tracking Tourists in the Digital Age." Annals of Tourism Research 34 (1): 141-59.

Shoval, Noam, and Michal Isaacson. 2007b. "Sequence Alignment as a Method for Human Activity Analysis in Space and Time." Annals of the Association of American Geographers 97 (2): 282-97.

Shoval, Noam, Bob McKercher, Erica Ng, and Amit Birenboim. 2011. "Hotel Location and Tourist Activity in Cities." Annals of Tourism Research 38 (4): 1594-612.

Shoval, Noam, Yonatan Schvimer, and Maya Tamir. 2017. "RealTime Measurement of Tourists' Objective and Subjective Emotions in Time and Space." Journal of Travel Research. Published online February 16. doi:10.1177/0047287517691155.

Shoval, Noam, Yonatan Schvimer, and Maya Tamir. 2018. "Tracking Technologies and Urban Analysis: Adding the Emotional Dimension." Cities 72:34-42.

Simon, Herbert A. 1955. "A Behavioral Model of Rational Choice." Quarterly Journal of Economics 69 (1): 99-118.

Simon, Herbert A. 1972. "Theories of Bounded Rationality." In Decision and Organization, edited by C. McGuire and Roy Radner, 161-76. Amsterdam: North Holland.

Slim, Siri, and Rein Ahas. 2016. "Ethnic Differences in Activity Spaces: A Study of Out-of-Home Nonemployment Activities with Mobile Phone Data." Annals of the Association of American Geographers 104 (3): 542-59.

Strauss, Kendra. 2008. "Re-engaging with Rationality in Economic Geography: Behavioral Approaches and the Importance of Context in Decision-Making." Journal of Economic Geography 8 (2): $137-56$

Tchetchik, Anat, Aliza Fleischer, and Noam Shoval. 2009. "Segmentation of Visitors to a Heritage Site Using HighResolution Time-Space Data." Journal of Travel Research 48 (2): 216-29.

Thaler, Richard. 1980. "Toward a Positive Theory of Consumer Choice." Journal of Economic Behavior and Organization 1:39-60.

Thaler, Richard. 1985. "Mental Accounting and Consumer Choice." Marketing Science 4 (3): 199-214.

Tideswell, Carmen, and Bill Faulkner. 1999. "Multidestination Travel Patterns of International Visitors to Queensland." Journal of Travel Research 37 (4): 364-74.

Tversky, Barbara. 1992. "Distortions in Cognitive Maps." Geoforum 23 (2): 131-38.

Walmsley, D. J., and J. M. Jenkins. 1992. "Tourism Cognitive Mapping of Unfamiliar Environments." Annals of Tourism Research 19 (2): 268-86.

Wolpert, Julian. 1964. "The Decision Process in Spatial Context." Annals of the Association of American Geographers 54 (4): 537-58.

Xiao-Ting, Huang, and $\mathrm{Wu}$ Bi-Hu. 2012. "Intra-attraction Tourist Spatial-Temporal Behaviour Patterns." Tourism Geographies 14 (4): 625-45. 
Yan, Zhixian, Dipanjan Chakraborty, Christine Parent, Stefano Spaccapietra, and Karl Aberer. 2013. "Semantic Trajectories: Mobility Data Computation and Annotation." ACM Transactions on Intelligent Systems and Technology 4 (3): 49.

Yin, Zhijun, Liangliang Cao, Jiawei Han, Jiebo Luo, and Thomas Huang. 2011. "Diversified Trajectory Pattern Ranking in Geo-tagged Social Media." In Proceedings of the 2011 SIAM International Conference on Data Mining, edited by Bing Liu, Huan Liu, Chris Clifton, Takashi Washio, and Chandrika Kamath, 980-91. Arizona: SIAM.

Young, Martin. 1999. "Cognitive Maps of Nature-Based Tourists." Annals of Tourism Research 26 (4): 817-39.

Yuskel, Atila, Fisun Yuskel, and Yasin Bilim. 2010. "Destination Attachment: Effects on Consumer Satisfaction and Cognitive, Affective and Conative Loyalty." Tourism Management 31 (2): 274-84.

Zhang, Weimin, Xiaoting Huang, and Yuan Li. 2017. "Understanding Tourist Mobility Using GPS: Where Is the Next Place?" Tourism Management 59:267-80.

Zhao, X. M., J. R. Shi, Y. Y. Duan, Y. X. Lei, and K. Hokao. 2015. "The Relationship between Tourist's Path Selection and Space
Image: A Case Study of Peripheral Lines Surrounding the West Lake." Lowland Technology International 17 (1): 27-38.

Zillinger, Malin. 2007. "Tourist Routes: A Time-Geographical Approach on German Car-Tourists in Sweden." Tourism Geographies 9 (1): 64-83.

Zoltan, Judith, and Bob McKercher. 2015. "Analysing Intradestination Movements and Activity Participation of Tourists through Destination Card Consumption.” Tourism Geographies 17 (1): 19-35.

\section{Author Biographies}

A. Yair Grinberger is a post-doctoral researcher at the GIScience Research Group in the Institute of Geography, Heidelberg University, Germany. His research interests include human mobility, geographic data, and how the two interact to produce geographic information.

Noam Shoval is a professor of geography at the Hebrew University of Jerusalem. His main research interests are urban geography and planning, urban tourism, and the implementation of advanced tracking technologies in various areas of spatial research such as tourism, urban studies, and medicine. 